\title{
Illa, J. Rivas, B. \& Sánchez, O. (Eds.) (2021). Juegos políticos. El deporte y las pugnas que mueven el mundo. Lima: Universidad Peruana de Ciencias Aplicadas (UPC).
}

El término deporte se asocia, usualmente, con un entramado de significados de valor positivo: forma de vida saludable, entretenimiento, juego, participación, disciplina, sana competencia e identificación, entre otras posibilidades. No en vano, se le atribuye la socialización como una de sus principales funciones, se le identifica como un recurso de cohesión social, se le vincula con valores como la confianza, cooperación e integración y se le reconoce beneficios (físicos y cognitivos) en el individuo y en su entorno (Pérez y Muñoz, 2018) Sin embargo, más allá de esta percepción extendida e indiscutible en ciertos ámbitos como el educativo, el deporte puede adquirir otras connotaciones y relacionarse con otros aspectos.

Jorge Illa, Bruno Rivas y Oscar Sánchez reúnen, en Juegos políticos. El deporte $y$ las pugnas que mueven al mundo, dieciocho artículos que ofrecen una visión menos naíf del deporte, sobre todo, porque se les vincula con la política, entorno teñido de suspicacia. Solo el título del libro hace referencia a ese ardid característico con el que suele actuarse en el medio político y que, posiblemente, muchos no queramos conectar con el deporte, porque preferimos que este continúe siendo el espacio que hemos reservado para el ocio. Si bien a lo largo de sus páginas, el deporte adquiere otros matices para el lector, pues se revela como un medio para la pugna ideológica, el control del poder y la expresión de jerarquías; también, desde la perspectiva de los autores y autoras, puede ser el espacio para el desarrollo de políticas públicas, la atención a la diversidad, el ejercicio del activismo y, en esta línea, el rechazo de prácticas de homofobia, racismo, discriminación, sexismo y violencia. De esta manera, el juego político que subyace al deporte, también, puede ser propositivo y la mirada de quienes leemos la realidad, además de crítica, constructiva. Desde mi entender, el mayor mérito del texto.

Los editores proponen un conjunto de artículos organizados en cinco secciones que se desarrollan en dos tomos. En el primero, se abordan dos apartados: el que relaciona deporte con geopolítica y el que lo analiza desde la cultura, la tecnología y la identidad. En los artículos de la primera parte, se visualiza a los eventos deportivos y a sus actores desde propósitos políticos e intereses económicos, en relación con el espacio a escala mundial y regional, sus nexos con la religión y en 
la exploración de los límites al interior del debate ético. Los artículos de la segunda parte enfocan su análisis desde dos conceptos fundamentales: industrias culturales, la de los eSports y la del cine, y la construcción de la identidad peruana a partir de la narración futbolística de los partidos de clasificación al Mundial de Rusia 2018 y la filmografía peruana que se ha producido recientemente en torno al fútbol peruano. En el segundo tomo, en las tres secciones restantes, se plantea una aproximación de corte más social que se revela en el tratamiento del deporte desde la inclusión, el racismo y la protesta, y el género y el empoderamiento. La mirada, en este segundo volumen, es diversa, pues el acercamiento al deporte y a su impacto se formula desde la política, la economía, el lenguaje y el discurso, y la acción social, entendida en su sentido más amplio.

Sin duda, esta estructuración ofrece una ruta para la lectura. No obstante, aunque en secciones diferentes y con estilos variopintos, los artículos pueden dialogar entre sí porque, en el escenario global, lo político, lo económico, lo social, lo cultural y lo tecnológico, todos aspectos que influyen y, al mismo tiempo, se ven impactados por el deporte, encuentran puntos de intersección que enriquecen la propuesta de Juegos políticos y posibilitan nuevos derroteros para la construcción de significados. En esta reseña, solo expondré algunas líneas temáticas que han sido presentadas en más de un artículo y que, particularmente, desde mi posición de lectora neófita en asuntos deportivos, me han suscitado mayor interés.

Un aspecto relevante que se ha abordado es la instrumentalización del deporte en el ámbito político. En esta línea, es significativo el análisis que Jorge Illa, Ariel Segal y Jaime Cordero realizan del deporte como un medio del que se valieron los regímenes totalitarios y gobiernos, en general, para demostrar su alineación con la ideología de ciertos modelos político-económicos y probar su «superioridad» por medio de los resultados deportivos que, como señala en su ensayo Oscar Sánchez Benavides, no en pocas ocasiones, ha comprometido la ética de sus deportistas. Conscientes de la atención que suscita el deporte y de su impacto en la economía, dictadores y demócratas de las naciones o ciudades sedes de importantes eventos deportivos han aprovechado estas oportunidades para exhibir su poder a través de su capacidad organizativa y adquisitiva, y expresar a través de la competencia deportiva sus rivalidades políticas, económicas e ideológicas. Aun así, el texto de Jaime Cordero apuesta por el legado positivo, más allá de lo económico, que puede dejar la organización de eventos de esta magnitud. Como organizadores de los Juegos Panamericanos 2019, cabe destacar el aprendizaje que se ganó en la gestión pública de un proyecto de esta envergadura y el interés y la movilización 
social que suscitó. Queda, no obstante, aún pendiente, descubrir nuestra capacidad para aprovechar la herencia material de este evento en favor de la sociedad y el deporte, y evaluar nuestro potencial para replicar el éxito de esta experiencia (Tineo, 2019)

Otra fortaleza es el análisis del deporte en el marco de la globalización. Al respecto, Jorge Illa y Ariel Segal, y Jorge Illa y Rocío Rebata destacan la comprensión del deporte como un fenómeno más próximo a la glocalización por la importancia que adquieren los nacionalismos en las competencias internacionales; el alcance internacional de los megaeventos a nivel de audiencia, la influencia económica que se ha manifestado con la mayor presencia de países en vías de desarrollo en la organización de eventos deportivos; los nuevos medios y formas de interacción que los deportistas han encontrado para interactuar con su afición, el efecto de las redes sociales en la publicidad y la expresión de la violencia xenófoba, racial o sexista que puede proferirse a través la comunicación global y digital, pero también la protesta y el cuestionamiento que puede ejercerse desde estos mismos medios a actitudes de este tipo, sin duda, un efecto notable de la sociedad prosumidora contemporánea. Así mismo, como lo destaca Carolina Christen, resulta muy interesante, como consecuencia de la masificación del internet, la inserción de los eSports a la industria deportiva, su crecimiento ascendente y las repercusiones que supondrá en la reconceptualización del deporte y en la imagen que hemos construido socialmente en torno al deportista y, por ende, en el desarrollo o posible transformación de eventos deportivos convencionales.

Un tercer eje de interés es el que se elabora desde el análisis del lenguaje y los discursos. Los prejuicios sutiles suelen esconderse tras mensajes aparentemente positivos en los que conceptos como diferencia, jerarquía y/o exclusión están latentes, de ahí la importancia del análisis crítico del discurso, ya que posibilita la aproximación a la ideología que subyace en este tipo de mensajes (GuardiánFernández et al.,2020). Según Glick y Fiske (1996; 2001, como se cita en GuardiánFernández et al., 2020), el prejuicio puede expresar hostilidad o benevolencia. En el primer caso, se enfatiza en la limitación o carencia y, por tanto, se infravalora al sujeto. En el segundo, aunque dentro del espectro de lo que serían modos de expresión socialmente aceptables, se estima al sujeto a partir de su fragilidad y, en consecuencia, se perpetúa una actitud proteccionista. Ya sea en una u otra situación, el lenguaje se asume como un medio poderoso a través del cual se pueden fortalecer los estereotipos. Ser consciente de ello puede ser una vía para erradicarlos. 
De una parte, se encuentran los artículos que consideran al discurso y al lenguaje como instrumentos potenciales de exclusión. En esta línea, el estudio de Kike La Hoz problematiza cómo abordar los logros de los deportistas con discapacidad desde el periodismo narrativo. Enfocarse en la discapacidad para victimizar o heroizar son formas recurrentes del lenguaje periodístico para transmitir compasión. En contraste, la moderación del lenguaje puede trasladar el centro de atención hacia el individuo y contribuir con la creación de una ética de la diversidad. José Miguel Guerra, en su artículo, evidencia que la ausencia de un discurso jurídico sobre el running y el espacio donde se circunscribe su práctica supone invisibilizar al sujeto deportista y, con ello, incrementar su vulnerabilidad. Para Marco Lovón, el discurso revela el pensamiento jerárquico racial bajo el cual se observa al sujeto otro, identificado con un colectivo inferiorizado, y que se traduce en un lenguaje, peligrosamente naturalizado, que lo deshumaniza. En su texto, Brenda Galagarza destaca cómo prevalece el sexismo informativo en la prensa deportiva y cómo repercute en el tratamiento de las noticias que tienen como protagonista a una mujer. El lenguaje, también en este texto, se asume como un instrumento de poder que refuerza prejuicios, distorsiona el protagonismo de las deportistas y genera expectativas sobre su actuar desde lo que el lenguaje predominantemente masculino determina.

Desde el otro enfoque, en el que el lenguaje convoca e incluye, están los artículos de Miguel Sánchez Flores y Bruno Rivas, en los cuales se examinan discursos como el relato futbolístico o el cinematográfico respectivamente, que revelan los deseos que el imaginario social peruano proyecta sobre los tipos de fútbol que anhela- el bélico, desde la posición del ganador, y el fútbol de equipo que simboliza unidad- y el ideal del nuevo futbolista- el que se distancia del fracaso y la mediocridad para convertirse en el líder que concretiza un sueño nacional-. Desde estos discursos, el fútbol favorece la construcción de una identidad colectiva.

Finalmente, el deseo de cambiar la situación de quienes podrían considerarse subordinados al interior del utilitarismo capitalista y de un sistema hegemónico masculino, constituye un eje valioso que articula algunos ensayos de este libro. Por un lado, están los que abordan el deporte desde la inclusión y en los que se revela la necesidad de desarrollar un modelo que direccione sus esfuerzos a la eliminación de barreras sociales y que busque, desde la educación, promover la aceptación de las diferencias, tal como lo señala María Luisa Palacios. En esta dirección, es ilustrativo el caso que expone Andrea Cabel en su ensayo, porque evidencia el alcance que puede tener el deporte en el desarrollo comunitario. La 
organización deportiva y cultural Alto Perú ha logrado, a través del surf, el muay thai y el ciclismo, instaurar, en los vecinos de un barrio marginal aquejado por la pobreza y la inseguridad, una nueva forma de convivencia y la reapropiación del espacio público. De esta manera, el deporte ha sido un mecanismo determinante para lograr la transformación y la inclusión social. Por otro lado, los artículos de la sección Género y empoderamiento aportan en la necesidad de repensar el deporte fuera de la masculinidad hegemónica. Para ello, María José Castro parte de la necesidad de comprender y aceptar la naturaleza fisiológica de la mujer, la menstruación como parte de ella, como un aspecto que debería visibilizarse y estudiarse para determinar la influencia que podría tener o no en el desempeño de las deportistas. No hacerlo significaría relegar nuestra condición de mujer y lo que nos diferencia de los deportistas hombres. Iván Villanueva amplía el espectro cuando plantea cómo la imposición de la práctica de fútbol en la escuela o en el barrio relega y subordina a los niños, cuyas identidades difieren de lo heterosexual y lo cisgénero.

Coincido plenamente con el prologuista del texto, quien resalta la visión abarcadora del deporte en esta obra: «hay vida más allá del fútbol, de la masculinidad y de la violencia» (Alabarces, como se cita en Illa et al, 2021, p. 10). Incuestionablemente, otra virtud del libro. Esta apertura es posible, porque se entiende al deporte en estrecha relación con la cultura, capaz de revelar la variedad de los procesos sociales, expresar las relaciones de interacción y tensión entre sus actores, y, al mismo tiempo, como un espacio simbólico para la transformación (Capretti, 2011). Contribuye a esta mirada no reduccionista, la riqueza multidisciplinaria con la que se abordan los análisis y que posibilitan al lector entradas distintas al tema. Queda entonces invitarlos a descubrir la complejidad del mundo deportivo a través de Juegos políticos y a identificar las tribunas desde las cuales se pueden generar ansiados cambios.

\section{Referencias bibliográficas}

Capretti, S. (2011). La cultura en juego. El deporte en la sociedad moderna y postmoderna. Trabajo y Sociedad, xv (16), 231-250. https://www.redalyc.org/ articulo.oa?id=387334688014

Guardián-Fernández, Alicia; Vargas Dengo, Marie-Claire; Delgado Álvarez, Carmen y Sánchez Prada, Andrés. (2020). Prejuicios hacia las personas con discapacidad: fundamentación teórica para el diseño de una escala. Revista 
Actualidades Investigativas en Educación, 20(1), 1-26. https://dialnet.unirioja. es/servlet/articulo? codigo $=7738362$

Pérez Flores, A. y Muñoz Sánchez, V. (2018). Deporte, cultura y sociedad: un estado actual de la cuestión. Revista de Humanidades, 34, 11-38. https://doi. org/10.5944/rdh.34.2018.21881

Tineo, R. (2019). Lima 2019: ¿cuál será el destino de las obras? La Cámara. http:// www.camaralima.org.pe/repositorioaps/o/o/par/r894_2/informe\%2oespecial. pdf

Rocío Aliaga Salazar

Universidad Peruana de Ciencias Aplicadas, Lima-Perú

silvia.aliaga@upc.pe

https://orcid.org/oooo-ooo1-7166-6406

\section{Trayectoria académica}

Rocío Aliaga Salazar es bachiller en Literatura por la Universidad Nacional Mayor de San Marcos (UNMSM) y licenciada en Educación por la Universidad Nacional Federico Villarreal (UNFv). Tiene una maestría en Educación con mención en Didáctica de la Comunicación por la UNMSM y ha concluido estudios de maestría en Lingüística en esta misma casa de estudios. Recientemente, ha concluido el Doctorado en Educación en la Universidad Femenina del Sagrado Corazón (Unifé). Actualmente, se desempeña como profesora a tiempo completo en la Universidad Peruana de Ciencias Aplicadas, donde dicta cursos en Humanidades y en la carrera de Traducción e Interpretación de Textos. Así mismo, es una de las responsables de la coordinación académica de la línea de Lenguaje. Está interesada en el diseño y ejecución de proyectos pedagógicos relacionados con el desarrollo de la competencia comunicativa. 